\title{
EFFECTS OF FIRE ON STRUCTURE AND COMPOSITION OF VEGETATION COMMUNITY IN PINE FORESTS, NAM NAO NATIONAL PARK, THAILAND**
}

\author{
KOBSAK WANTHONGCHAI ${ }^{*}$ AND VORADET TARUSADAMRONGDET² \\ ${ }^{1}$ Department of Silviculture, Faculty of Forestry, Kasetsart University, Bangkok 10900, Thailand \\ ${ }^{2}$ Department of National Parks, Wildlife and Plant Conservation, Bangkok 10900, Thailand
}

Received 08 January 2019 / Accepted 14 August 2019

\begin{abstract}
Anthropogenic forest fires, including those occurring in the pine forests of Thailand, have been widely reported. Although pine forests are fire dependent, too frequent burning could be unhealthy for the forest as it might result in nutrient depletion and ecosystem degradation. Hence, this study aimed to examine the effects of forest fire on the vegetation structure and composition of a degraded pine forest (PF) and in a mixed pine-oak forest (O-PF) of Phu Kum Khao, Nam Nao National Park, Phetchabun Province, Thailand. The effects of fire in one year were studied using three 50 × $50 \mathrm{~m}$ experimental plots established in each forest type. Results showed that fire events caused a significantly higher tree mortality rate in the degraded pine forest than in the mixed pineoak forest. Moreover, the seedling ratio (number of sprout to number of seedling ratio) in the mixed pine-oak forest was higher than in the degraded pine forest. Although the sapling and seedling diameters were slightly different between the sites, no significant effect of burning was observed on the sapling and seedling density, diameter and height. This might be due to the high variation of fire behavior in each plot. Since forest fires are a potential factor that might cause forest degradation in the study area, further studies on the effects of fire frequency on vegetation structure and composition is needed to provide sufficient fire control measures for efficient forest fire management to prevent further ecosystem degradation.
\end{abstract}

Keywords: burning, degraded pine forest, Nam Nao National Park, pine-mixed oak forest

\section{INTRODUCTION}

Forest fire is a critical factor that shapes the ecosystem structure of many forested areas (Pyne 2001). Too frequent forest fires have caused ecosystem damage in many areas including tropical pine forests (Goldammer \& Penafiel 1990; Wanthongchai \& Goldammer 2011). The presence of the flammable forest floor consists mainly of grasses and pine needles, and the frequent anthropogenic burning activities or agricultural residual burning around the forest, the pine forests of Phu Kum Khao, Nam Nao National Park, Thailand experiences fire events almost every year (Tarusadamrongdet 2013). Although the physical characters of pine

\footnotetext{
${ }^{*}$ Corresponding author, e-mail: fforksw@ku.ac.th

${ }^{*}$ This paper was presented at the $3^{\text {td }}$ International Conference on Tropical Biology 2018, 20-21 September 2018, Bogor, West Java, Indonesia
}

trees such as thick bark and needle-protected buds make them resistant to fires, fire events are still a threat to the national park (Kutintara 2008; Brown \& Smith 2000). A preliminary survey in this area showed that the plant community was dominated by widely scattered large pine trees at the top canopy, while no other species were found below the canopy layer. In addition, the forest floor was covered by dense grasses, a condition that indicated some limitations to the natural regeneration process. This forest structure could be associated with annual forest fires. Evidences of other external pressures causing plant mortality and degradation, such as lightning and pine resin collection were also observed in this forested area. Forest fires, natural mortality and anthophogenic pressures negatively impacted the natural regeneration process and nutrient cycling which could eventually cause forest 


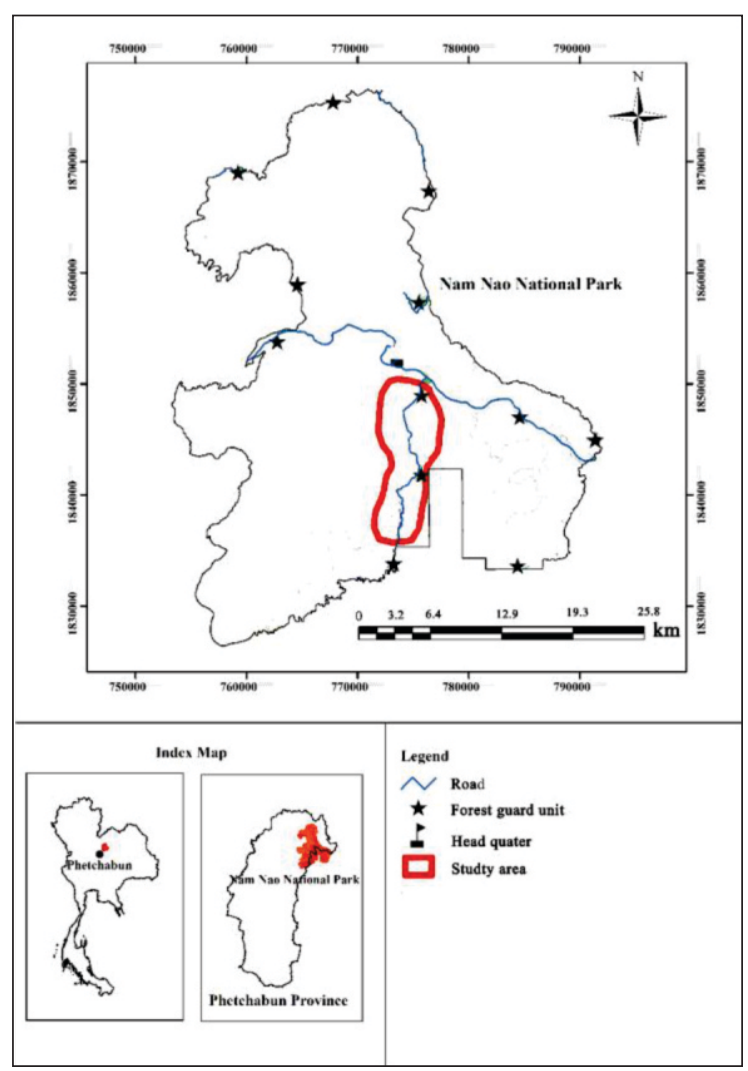

Figure 1 Location of Nam Nao National Park and study area

degradation. If the situation persists for so long without proper management, the pine forest community might be replaced by a savanna ecosystem (Cochrane 2009).

Although pine forests are fire dependent ecosystems, the fire resistant ability of the vegetation depends on suitable burning regimes such as; the fire frequency, fire intensity and fire severity of the burning area, which are critical factors determining the presence of pine trees in the ecosystem must be compatible with the ecological and biological processes of the plant community (Cochrane 2009).

This study aimed to examine the effects of fire on vegetation structure and composition, and natural regeneration within one year after burning occurred in a degraded pine forest and a mixed oak-pine forest of Phu Kum Khao, Nam Nao National Park, Thailand (Fig. 1).

\section{MATERIALS AND METHODS}

The study was conducted in a degraded pine forest $(\mathrm{PF})$, a savanna-like community, which is mostly covered by grass with very few pine trees and a mixed oak-pine forest (O-PF) in Phu
Kum Khao, Nam Nao National Park, Phetchabun, Thailand (Kutintara 2008). Three $50 \times 50 \mathrm{~m}$ experimental plots were set up in each forest type. Within each plot, there were four 25 x $25 \mathrm{~m}$ sub-plots. Fire breaks were constructed around all the experiment plots (Fig. 2).

The structure and composition of trees $(\mathrm{dbh}>4.5 \mathrm{~cm})$ were recorded in each sub-plot. Furthermore, a $4 \times 4 \mathrm{~m}$ (for sapling) and $2 \times 2 \mathrm{~m}$ (for seedling) plots were established in each subplot, for the measurement of their diameter at trunk base $\left(\mathrm{D}_{0}\right)$, dbh and height for all saplings and seedlings (Fig. 2). The individual canopy area and height of the burning scar at the tree trunk were also measured. The crown cover of the vegetation community was photographed using a digital camera with $18 \mathrm{~mm}$ fish eye lens, set at $1 \mathrm{~m}$ from the ground.

Burning experiments using the head fire burning technique were conducted in March 2012 by the fire control officers of Petchabun Province. Prior to burning, a firebreak was setup around the $50 \times 50 \mathrm{~m}$ plot and an ignition point was started based on the wind direction. Species and the number of trees (woody plant that has 


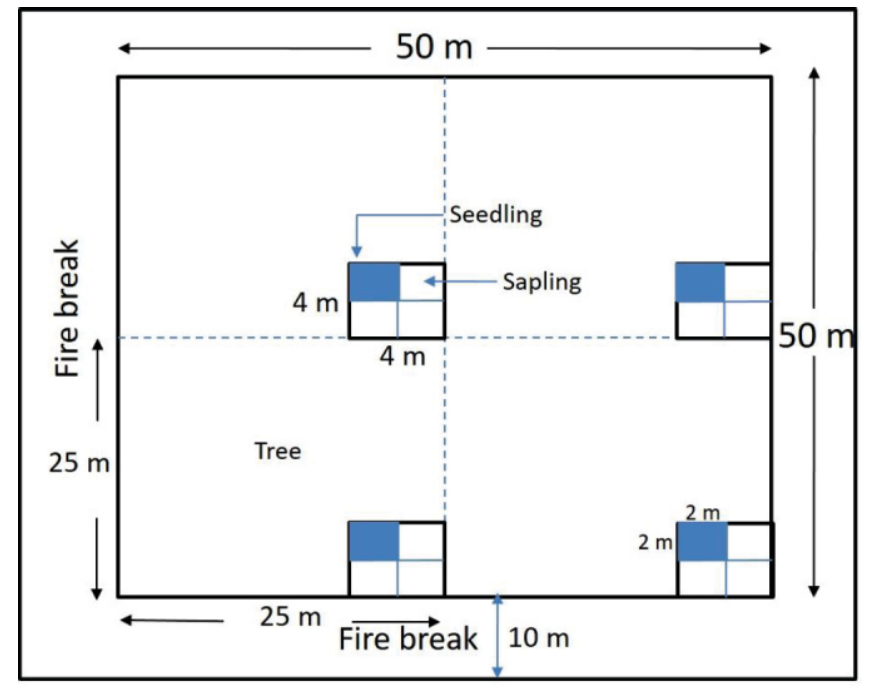

Figure 2 Plot layout for vegetation measurement

dbh $>4.5 \mathrm{~cm}$ ), saplings (woody plant that has $\mathrm{dbh}<4.5 \mathrm{~cm}$, height $>1.30 \mathrm{~m}$ ), seedlings (woody plant that has height $<1.30 \mathrm{~m}$ ) and ground flora (herbaceous, grass and climber) were re-examined 12 months after burning. Fuel characteristics and fire behaviors during the burning experiment were also recorded (Wanthongchai et al. 2013).

Crown cover was calculated using the Hemiview version 2.1 program. Vegetation density, basal area, diameter class distribution, and Shannon-Wiener Diversity Index were also calculated (Wanthongchai et al. 2014). Effects of fire on the structure and composition of plant community were then compared between the degraded pine forest and mixed oak-pine forest, during the pre-burn and post-burn period.

\section{RESULTS AND DISCUSSION}

\section{Structure of Plant Community before the Burning Experiment}

Before the experimental fire event (pre-burn), 30 and 25 tree species were found in the PF and the O-PF, respectively. The disturbance regime that has degraded the pine forest may have resulted in higher number of species. Vertically, the PF vegetation structure consisted of 2 canopy layers. The dominant trees were Pinus kesiya with heights over $30 \mathrm{~m}$, and widely scattered in the study area. The second dominant species were hill evergreen tree species with heights less than $10 \mathrm{~m}$, such as Craibiodendron stellatum and Terminalia chebula. The vertical structure of O-PF consisted of 3 canopy layers, more than $30 \mathrm{~m}$ high where the P. kesiya dominated the top canopy. The middle canopy was dominated by Lithocarpus grandifolius, Quercus auricoma, Dipterocarpus obtusifolius and Aporosa villosa with height of about $15-20 \mathrm{~m}$. The lower canopy included the smaller trees of the top and middle canopy and some other small tree such as Phyllanthus emblica, Ardenia sootepensis and Memecylon scutellatum. PF has a tree density of 304 trees/ha, while O-PF had four times higher tree density (Table 1). Seedling density in the PF was lower than in the mixed oak-pine forest. The degraded pine forest has a sapling canopy cover of $37.45 \%$ and was slightly higher than in the mixed oak-pine forest (31.48\%). The higher percentage of sapling canopy cover and lower seedling density could be due to the annual fire disturbance.

Pre-burning survey of species diversity found a total of 47 tree species in these study plots (Table 1). Number of tree species was higher in the PF than in the O-PF. Both forests showed similar number of saplings and seedlings diversity (Shannon-Wiener Index $=2.81 \& 2.83$ and $2.08 \& 2.44$ for PF and O-PF, respectively). 
Table 1 Pre-burn vegetation structure and composition in the degraded pine forest (PF) and the mixed oak-pine forest (O-PF) at Phu Kum Khao, Nam Nao National Park, Thailand

\begin{tabular}{|c|c|c|c|}
\hline & Structure $^{a}$ & $\mathrm{PF}$ & $\mathrm{O}-\mathrm{PF}$ \\
\hline \multirow[t]{5}{*}{ Tree } & Density (ind./ha) & $304^{a}(43.50)$ & $1,327^{b}(242.40)$ \\
\hline & Basal area $\left(\mathrm{m}^{2} / \mathrm{ha}\right)$ & $11.10^{\mathrm{a}}(0.53)$ & $17.40^{\mathrm{b}}(1.96)$ \\
\hline & Canopy area $\left(\mathrm{m}^{2} / \mathrm{ha}\right)$ & $5,943.10^{\mathrm{a}}(630.16)$ & $12,450.60^{\mathrm{b}}(1,210.14)$ \\
\hline & Number of species & 30 & 25 \\
\hline & Shannon-Wiener Index $(\mathrm{H})$ & 2.81 & 2.08 \\
\hline \multirow[t]{7}{*}{ Sapling } & Density (ind./ha) & $6,667 \mathrm{a}(1458.30)$ & $4,583^{a}(1102.40)$ \\
\hline & Diameter at Trunk Base: $\mathrm{D}_{0}(\mathrm{~cm})$ & $2.45^{\mathrm{a}}(0.34)$ & $2.38^{\mathrm{a}}(0.89)$ \\
\hline & Diameter at Breast Height: DBH $(\mathrm{cm})$ & $0.97^{\mathrm{a}}(.26)$ & $1.23^{\mathrm{a}}(0.41)$ \\
\hline & Height $(\mathrm{m})$ & $1.87^{\mathrm{a}}(0.17)$ & $1.98^{\mathrm{a}}(0.28)$ \\
\hline & Canopy cover $(\%)$ & $37.45^{\mathrm{a}}(4.48)$ & $31.48^{\mathrm{a}}(11.30)$ \\
\hline & Number of species & 11 & 13 \\
\hline & Shannon-Wiener Index $(\mathrm{H})$ & 2.22 & 2.39 \\
\hline \multirow[t]{6}{*}{ Seedling } & Density (ind./ha) & $50,833^{a}(16729.20)$ & $70,833^{a}(16414.80)$ \\
\hline & Diameter at Trunk Base $\mathrm{D}_{0}(\mathrm{~cm})$. & $0.50^{\mathrm{a}}(0.04)$ & $0.44^{a}(0.13)$ \\
\hline & Height $(\mathrm{m})$ & $0.52^{\mathrm{a}}(0.05)$ & $0.36^{\mathrm{a}}(0.04)$ \\
\hline & Canopy cover $(\%)$ & $20.79^{a}(11.13)$ & $44.52^{\mathrm{a}}(16.14)$ \\
\hline & Number of species & 22 & 19 \\
\hline & Shannon-Wiener Index $(\mathrm{H})$ & 2.83 & 2.44 \\
\hline
\end{tabular}

Notes: ${ }^{a}$ Different superscript $(a, b)$ indicate significant differences $(t$-test, $\mathrm{p}<0.05)$ of vegetation structures in the two forest types;

Standard deviation values are presented in the parentheses.

Effects of Burning on the Structure and Composition of the Plant Community

Fire Effects on Tree Mortality and Density

The data collected one-year after the burning experiment showed that mortality rates of trees in PF $(4.59 \%)$ was significantly higher than in O-PF $(1.15 \%)$. The tree species that died after the fire in the $\mathrm{O}-\mathrm{PF}$ were $Q$. auricoma, D. obtusifolius, G. sootepensis and P. kesiya. The tree species that died after the fire in the PF consisted of C. stellatum, Pterocarpus macrocarpus, Albizia odoratissima, S. wallichii, Protium serratum and P. kesiya. The D. obtusifolius trees which died after burning at the 0-PF had smaller diameter than the average diameter of the same species.

Although the burning caused the death of some species in the experimental plots, the average tree densities in the PF before and after the burning experiment did not significantly differ. In contrast, the tree density in the O-PF before and after the fire significantly differed and reduced from 1,327 to 1,313 individual trees/ha (Table 2). This indicated that tree species in degraded forests, where burnings frequently occur, had adapted to fire environment and therefore could tolerate fire events.

Table 2 Tree density during the pre-burn and the one-year post-burn experimental period

\begin{tabular}{llll}
\hline \multirow{2}{*}{ Plot/Forest types } & \multicolumn{3}{c}{ Tree* Density (trees/ha) } \\
\cline { 2 - 4 } & Pre-burning & Post-Burning & Mortality $(\%)$ \\
\hline PF-1 & 375 & 356.25 & 5.00 \\
PF-2 & 312.5 & 293.75 & 6.00 \\
PF-3 & 225 & 218.75 & 2.78 \\
average-PF & $304.2^{\mathrm{a}}(43.5)$ & $289.6^{\mathrm{a}}(39.7)$ & $4.59^{\mathrm{a}}(0.95)$ \\
\hline O-PF-1 & $1,662.5$ & $1,643.75$ & 1.13 \\
O-PF-2 & 856.25 & 843.75 & 1.46 \\
O-PF-3 & $1,462.5$ & 1,450 & 0.85 \\
average-O-PF & $1,327.1^{\mathrm{a}}(242.4)$ & $1,312.5^{\mathrm{b}}(240.9)$ & $1.15^{\mathrm{b}}(0.18)$ \\
\hline
\end{tabular}

Notes: ${ }^{a}$ Different superscript $(\mathrm{a}, \mathrm{b})$ across a row indicate significant differences $(t$-test, $\mathrm{p}<0.05)$ of tree density before and after the burning experiments in each of the forest types;

Standard deviation values are presented in the parentheses;

${ }^{*}$ Tree $(\mathrm{DBH}>4.5 \mathrm{~cm})$. 
Fire Effects on Saplings and Seedlings Density, Diameter and Height

After the fire, sapling density reduction in the PF was higher than in the O-PF (Table 3). The saplings that survived after the burning experiment tended to be taller and larger in diameter than the saplings before the fire. The mean DBH range was $0.6-2.4 \mathrm{~cm}$ and mean height range was $1.5-2.4 \mathrm{~m}$. The statistical analysis suggested that fire did not significantly affect the vegetation structures of saplings (Table 3). The estimated diameter and height growth rates were $0.4-0.8 \mathrm{~cm} /$ year, and 0.2 $0.4 \mathrm{~m} /$ year, respectively.

The density per area and canopy area of seedlings after burning were higher in both degraded pine forest and mixed oak-pine forest, while the diameter at trunk base and height of seedlings were lower. Only the seedling height in the mixed oak-pine forest significantly decreased after the fire. However, no significant difference existed between the forest for all the other parameters. The high fire intensity variations during the burning experiment could account for the insignificant difference. The lower height of seedlings could be due to new seedlings replacement after the fire.

Fire Effects on Diameter Classes of Saplings and Seedlings

The number of post-burn saplings in each diameter class in the PF was lower than before the burning experiment (Fig. 3a). No saplings were found in the large diameter class in the PF site during both pre- and post-burn period (Fig. 3a). On the other hand, no clear pattern was found in the O-PF as the number of postburn saplings in small diameter class (1.1 $3.0 \mathrm{~cm}$ ) was lower than those of pre-burn, while the number in several other diameter classes, particularly in the medium diameter class (3.1 $7.0 \mathrm{~cm}$ ), was higher in the post-burn. These increases could be attributed to the low fire intensity which minimized sapling mortality (Fig. 3b).

The seedling distribution was spread to more class sizes in both the PF (Fig. 3c) and O-PF (Fig. 3d). In the O-PF, number of seedling in smaller diameter-classes was higher than that in the larger diameter-classes. Overall, the mean number of seedlings in the O-PF was lower in the post-burn period except for the diameter class $0.3-0.6 \mathrm{~cm}$ (Fig. $3 \mathrm{~d}$ ). In PF, the number of seedlings in the small and medium diameter classes in the post-burn was higher than in the pre-burn. The disappearance of grass just after the fire might be due to forest floor opening that also stimulated new seedling recruitment. Nevertheless, if the fire event occurs again the following year, these seedlings could be destroyed by the subsequent burning.

Table 3 Pre- and post-burn structure of saplings and seedlings in the degraded pine forest (PF) and the mixed oak-pine forest (O-PF) at Phu Kum Khao, Nam Nao National Park, Thailand

\begin{tabular}{llllll}
\hline & Structure & & \multicolumn{2}{c}{ O-PF } \\
\cline { 3 - 6 } & & Pre-burn & Post-burn & Pre-burn & Post-burn \\
\hline Sapling & Density (ind./ha) & $6,666.70^{\mathrm{a}}$ & $2,500.00^{\mathrm{a}}$ & $4,583.30^{\mathrm{a}}$ & $3,541.70^{\mathrm{a}}$ \\
& & $(1,458.30)$ & $(360.80)$ & $(1,102.40)$ & $(1,041.70)$ \\
& Diameter at trunk base: $\mathrm{D}_{0}(\mathrm{~cm})$ & $2.45^{\mathrm{a}}(0.34)$ & $2.23^{\mathrm{a}}(0.55)$ & $2.38^{\mathrm{a}}(0.89)$ & $3.00^{\mathrm{a}}(0.72)$ \\
& Diameter at Breast Height: DBH $(\mathrm{cm})$ & $0.97^{\mathrm{a}}(0.26)$ & $1.00^{\mathrm{a}}(0.25)$ & $1.23^{\mathrm{a}}(0.41)$ & $1.67^{\mathrm{a}}(0.54)$ \\
& Height (m) & $1.87^{\mathrm{a}}(0.17)$ & $2.13^{\mathrm{a}}(0.09)$ & $1.98^{\mathrm{a}}(0.28)$ & $1.90^{\mathrm{a}}(0.26)$ \\
& Canopy cover $(\%)$ & $37.45^{\mathrm{a}}(4.48)$ & $28.57^{\mathrm{a}}(7.05)$ & $31.48^{\mathrm{a}}(11.30)$ & $31.72^{\mathrm{a}}(14.73)$ \\
\hline Seedling & Density (ind./ha) & $50,833.30^{\mathrm{a}}$ & $74,166.70^{\mathrm{a}}$ & $70,833.30^{\mathrm{a}}$ & $79,166.70^{\mathrm{a}}$ \\
& & $(16,729.00)$ & $(20,531.10)$ & $(16,414.80)$ & $(14,529.70)$ \\
& Diameter at trunk base:D $\mathrm{D}_{0}(\mathrm{~cm})$ & $0.50^{\mathrm{a}}(0.04)$ & $0.48^{\mathrm{a}}(0.05)$ & $0.44^{\mathrm{a}}(0.13)$ & $0.34^{\mathrm{a}}(0.07)$ \\
& $0.52^{\mathrm{a}}(0.05)$ & $0.38^{\mathrm{a}}(0.01)$ & $0.36^{\mathrm{a}}(0.04)$ & $0.28^{\mathrm{b}}(0.05)$ \\
& Height: Ht $(\mathrm{m})$ & $20.79^{\mathrm{a}}(11.13)$ & $72.18^{\mathrm{a}}(20.18)$ & $44.52^{\mathrm{a}}(6.15)$ & $49.32^{\mathrm{a}}(10.90)$ \\
\hline
\end{tabular}

Notes: aDifferent superscript $(\mathrm{a}, \mathrm{b})$ across a row indicate significant differences $(t$-test, $\mathrm{p}<0.05)$ of the pre and post burning structures of sapling and seedling in each of the forest types. 

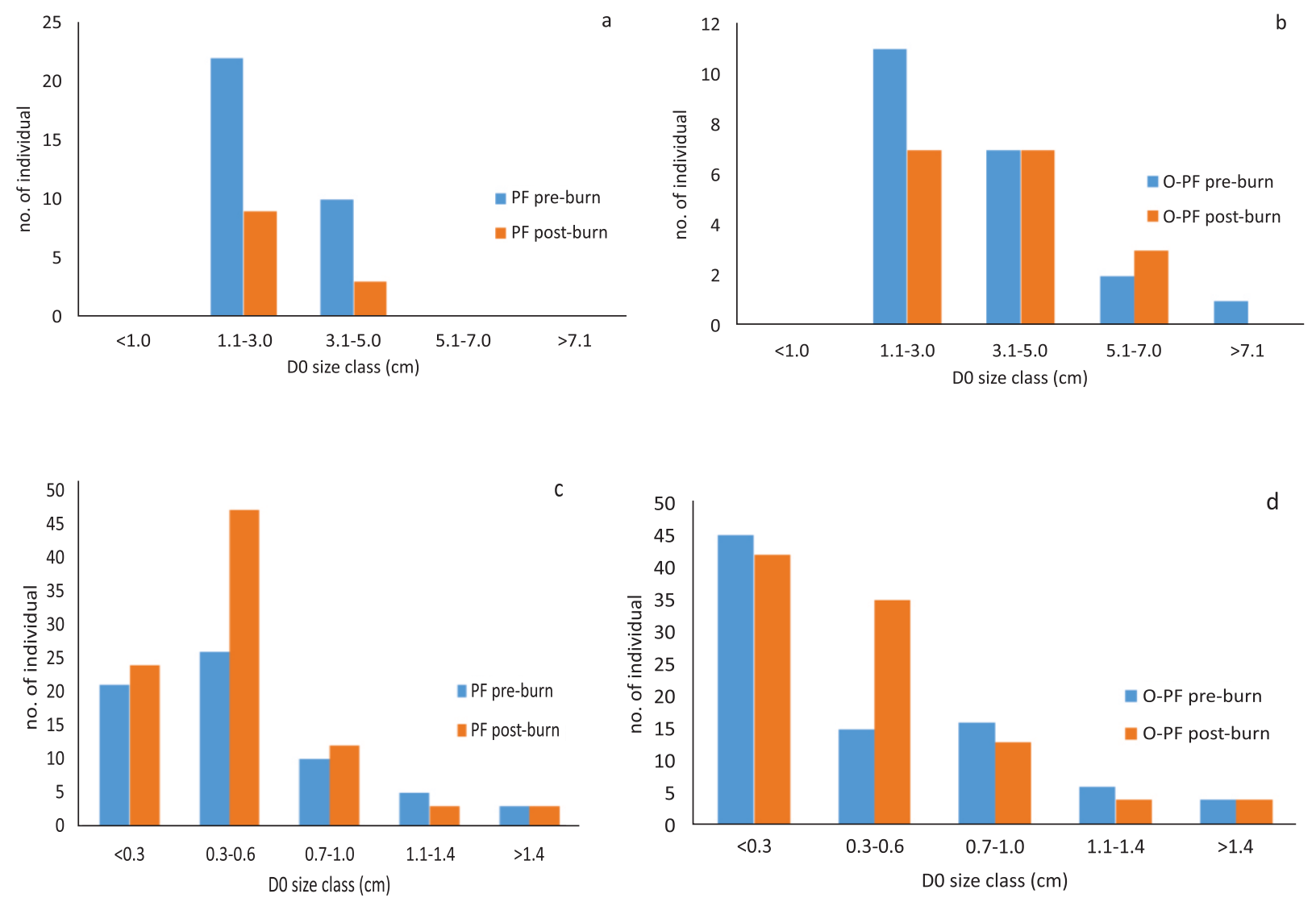

Figure 3 Diameter class distribution of saplings trunk base $\left(\mathrm{D}_{0}\right)$ during the pre-burn and one year post-burn period in the degraded pine forest (PF) (a) and the mixed oak-pine forest (O-PF) (b), and diameter class distribution of seedlings during the pre-burn and one year post-burn period in the degraded pine forest (PF) (c) and the mixed oak-pine forest $(\mathrm{O}-\mathrm{PF})(\mathrm{d})$

\section{Fire Effects on Seedling Ratio}

Seedling ratio, which is a measure of the coppicing ability, is the proportion of total number of new sprout and number of seedling stumps in the experimental plots. Rapid coppicing ability is one critical characters which enable plants to adapt to the fire conditions. High seedling ratio indicates that the plants have high coppicing potential. The seedling ratios in the $\mathrm{PF}$ and $\mathrm{O}-\mathrm{PF}$ forests during the pre-burn were 1.1 and 2.5 , respectively. Changes in seedling ratio during the post-fire event in both study sites, however, did not significantly differ (Fig. 4).

The ratio of the number of newly sprouted shoots, or suckers, to the number of individual seedlings (seedling ratio) in the PF were significantly lower than the ratio in the O-PF. The more frequent burning in the $\mathrm{PF}$ might have resulted in the more frequent tree coppicing which consumes the stored energy. Therefore, this reduction of stored energy could have resulted in the reduction of seedling ratio in the subsequent fire events (Wanthongchai 2008). On the other hand, the forest fire in the O-PF was less frequent than that in the PF, which saved more stored energy for coppicing as a result of higher seedling ratio. However, if the fire events remain too frequent, the coppicing ability for many seedlings will decrease and seedlings eventually die. The capacity for vegetative propagation of the trees (as indicated by ratio of sprout to seedlings) increased on the less frequently burned sites after the burning experiment in the dry dipterocarp forest (Wanthongchai et al. 2008). In contrast, on the site that burned too frequently, the number of sprouts decreased after the fire. 


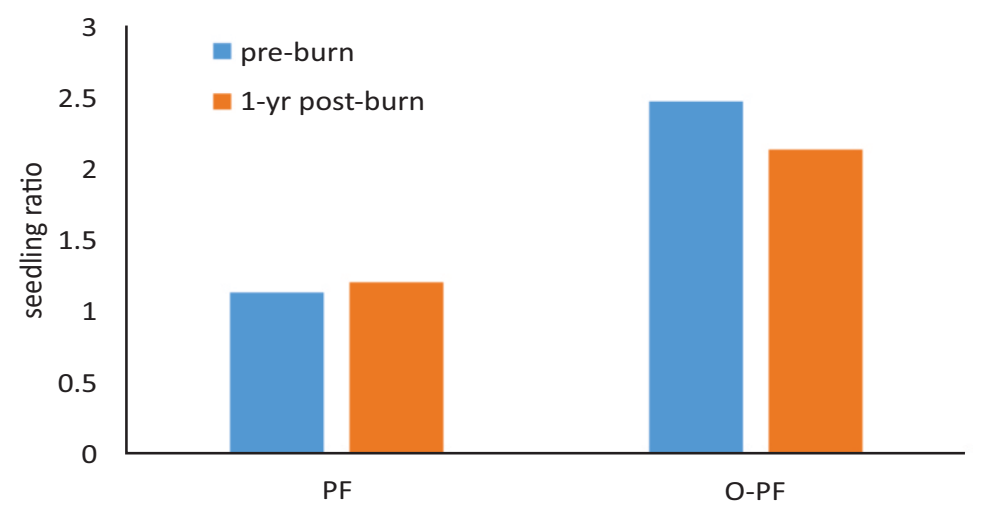

Figure 4 Pre-burn and one-year post-burn seedling ratios of the vegetation in the degraded pine forest (PF) and the mixed oak-pine forest $(\mathrm{O}-\mathrm{PF})$

Pine forests are fire dependent ecosystems. Fire regime, consisting of fire types, fire frequency, fire intensity, fire season and fire severity (Chandler et al. 1983), is a critical factor affecting the growth process, development and natural regeneration of pine forest trees (Kutintara 2008). This study, particularly, demonstrated that a fire event had different impacts on the plant communities in the degraded forest and in the mixed oak-pine forest.

\section{Effects of Fire Characteristics/Behavior on the Burned Sites}

Most fires that occur in the pine forests of Thailand affect the saplings and seedlings more than the large trees as the fires with low to medium intensity usually burn only the surface fuel. The fire characteristics had significantly greater impact in the PF stand than in the O-PF stand (Wanthongchai et al. 2013). Burning at the $\mathrm{O}-\mathrm{PF}$ and the PF were classified as low-intensity $(48 \mathrm{~kW} / \mathrm{m})$, and medium-intensity $(627 \mathrm{~kW} / \mathrm{m})$, respectively (Table 4). During the burning experiment, the surface soil temperatures at all sites were higher than $250{ }^{\circ} \mathrm{C}$. However, fire did not cause temperature changes in the deeper soil layers. Several tree species in the study area were resistant to the fire because of their physical characteristics, such as, thick bark and fast coppicing ability. Nevertheless, these pine characteristics are not yet developed in the sapling and seedling stages, but are likely to show when they are mature. Therefore, fire resistance is positively correlated with tree age (Whelan 1995).
Tree mortality observed in the PF was 5\% and in the O-PF was $1 \%$. Tree mortality could be an indicator of fire intensity. Higher mortality in the degraded pine forest could imply higher fire intensity as the dense grass covering the forest floor was highly inflammable. The more frequent fire events in the degraded pine forest have prevented natural regeneration, which may lead to a probable replacement of pine forest by a savanna ecosystem. Therefore, an effective forest fire management that only allows occasional fire events is critical for the conservation and restoration of this degraded pine forest. The "fire-free period" must be allowed long enough for natural regeneration to take place. For example, the appropriate burning frequency to maintain vegetation structure and site fertility in dry dipterocarp forest was $2-3$ times per decade (Wanthongchai et al. 2008).

Fire caused a reduction in the number of saplings in both degraded pine forest and mixed oak-pine forest, however, saplings reduction in the degraded pine forest was higher than in the mixed oak-pine forest, a condition which might be due to fire intensity. In a previous study, the fire intensity and flame height in a degraded pine forest $(627 \mathrm{~kW} /$ mand $1.4 \mathrm{~m})$ was higher than in the mixed oak-pine forest $(48 \mathrm{~kW} / \mathrm{m}$ and $0.4 \mathrm{~m})$ (Wanthongchai et al. 2013). This higher fire intensity in the degraded pine forest also accounted for the decrease in sapling diameter in all the diameter classes. On the other hand, the low fire intensity in the mixed oak-pine forest could account for the increase in diameter of saplings in the larger diameter classes as the fire intensity was not high enough to kill the 
Table 4 Quantitative average of fire characteristics, flame temperature and soil temperature in degraded pine forest (PF) and pine-oak forest (O-PF) (Wanthongchai et al. 2013)

\begin{tabular}{|c|c|c|}
\hline \multirow{2}{*}{ Fire characteristic ${ }^{b}$} & \multicolumn{2}{|c|}{ Stand } \\
\hline & PF & O-PF \\
\hline Head-fire rate of spread (m/min) & $4.5^{\mathrm{a}}( \pm 1.0)$ & $0.9^{\mathrm{b}}( \pm 0.2)$ \\
\hline Back-fire rate of spread (m/min) & $0.8^{\mathrm{a}}( \pm 0.1)$ & $0.3^{\mathrm{b}}( \pm 0.1)$ \\
\hline Average flank-fire rate of spread $(\mathrm{m} / \mathrm{min})$ & $1.2^{\mathrm{a}}( \pm 0.2)$ & $0.5^{\mathrm{b}}( \pm 0.01)$ \\
\hline Head-fire flame height $(\mathrm{m})$ & $2.5^{\mathrm{a}}( \pm 0.2)$ & $0.6^{\mathrm{b}}( \pm 0.04)$ \\
\hline Back-fire flame height (m) & $1.2^{\mathrm{a}}( \pm 0.3)$ & $0.2^{\mathrm{b}}( \pm 0.1)$ \\
\hline Average flank-fire flame height (m) & $0.6^{\mathrm{a}}( \pm 0.03)$ & $0.2^{\mathrm{b}}( \pm 0.1)$ \\
\hline Flame length (m) & $1.4^{\mathrm{a}}( \pm 0.1)$ & $0.4^{\mathrm{b}}( \pm 0.1)$ \\
\hline Fireline intensity $(\mathrm{kW} / \mathrm{m})$ & $626.6^{\mathrm{a}}( \pm 129.9)$ & $47.9^{\mathrm{b}}( \pm 23.0)$ \\
\hline Heat release per unit area $(\mathrm{kJ} / \mathrm{m})$ & $288.6^{a}( \pm 22.9)$ & $85.8^{\mathrm{b}}( \pm 40.7)$ \\
\hline \multicolumn{3}{|l|}{ Flame temperature $\left({ }^{\circ} \mathrm{C}\right)$} \\
\hline $20 \mathrm{~cm}$ aboveground & $586.5^{\mathrm{a}}( \pm 29.1)$ & $389.7^{\mathrm{b}}( \pm 55.8)$ \\
\hline $50 \mathrm{~cm}$ aboveground & $471.6^{\mathrm{a}}( \pm 45.6)$ & $301.2^{\mathrm{a}}( \pm 64.5)$ \\
\hline \multicolumn{3}{|l|}{ Maximum soil temperature $\left({ }^{\circ} \mathrm{C}\right)$} \\
\hline soil surface & $484.9^{\mathrm{a}}( \pm 146.6)$ & $255.2^{\mathrm{a}}( \pm 105.4)$ \\
\hline $2 \mathrm{~cm}$ beneath the soil surface & $24.1^{\mathrm{a}}( \pm 1.3)$ & $25.9^{\mathrm{a}}( \pm 0.1)$ \\
\hline $5 \mathrm{~cm}$ beneath the soil surface & $20.2^{\mathrm{a}}( \pm 0.1)$ & $23.6^{\mathrm{b}}( \pm 0.3)$ \\
\hline $10 \mathrm{~cm}$ beneath the soil surface & $19.2^{\mathrm{a}}( \pm 0.3)$ & $21.7^{\mathrm{b}}( \pm 0.2)$ \\
\hline
\end{tabular}

Notes: ${ }^{a}$ Different superscripts $(a, b)$ across a row indicate significant differences $(p<0.05)$ in the average fire behavior characteristics, flame temperature and soil temperature between degraded pine forest and pine-oak forest; Flame length and fireline intensity were calculated using Byram’s formula (Byram 1959); Standard errors are given in parentheses.

saplings but stimulated their growth instead. The decrease in the number of saplings did not always imply sapling mortality as the new shoots grew but their sizes were not big enough to be considered as saplings. The decrease in sapling height could also be attributed to this phenomenon. For the seedlings, both diameterclass distribution and numbers were higher after the fire. This is probably due to the post-burn grass mortality, which provided space for the seedlings to germinate and grow. However, if subsequent fires occur the following year, these seedlings could also be killed by the fire.

\section{Effects of Burning Regimes}

Fire frequency is one ajor factor that greatly affects plant community structure and composition. Excessively frequent fire occurrence will likely cause ecosystem degradation (Kimmins 1997), a situation that is more commonly found in degraded pine forests than in mixed oak-pine forests. Degraded pine forests are composed of scattered big trees, and low sapling and seedlings density, due to tall and dominant grasses (Wanthongchai et al. 2013) The main fuel proportion in the PF stand was $45 \%$ grass and $44 \%$ litter whereas in the O-PF stands $55 \%$ was leaf litter. In the dry season, these grasses and litter dry up and become flammable fuel and increase forest fire intensity, destroying the trees, saplings and seedlings. This situation could further encourage the presence of fast growing grasses and weeds, especially the xerophytic species, and, hence, ready to ignite. If this grass-fire cycle persists, the degraded pine forest will eventually be succeeded by a savanna grassland (Whelan 1995). This succession process was already observed in the degraded pine forest of Phu Kum Khao.

High fire frequency and intensity could also interfere with the natural regeneration process as they cause the death of saplings and seedlings. In the degraded pine forest of this study, $P$. kesiya grew very tall and continuously got struck and killed by lightning, a condition that will also contribute to ecosystem succession by a savanna grassland. Therefore, an immediate fire protection protocol is needed to assist the natural regeneration and allow the pine seedlings and saplings to grow since they need time to adapt to the fire dependent environment (Royal Forest Department 2008). In addition, as the degraded pine forest floor is dominated by grass that prevent seedlings from germinating and growing, it is also important to eliminate the grass and weeds. Long term fire management to 
secure the natural regeneration of seedlings and saplings is equally important. A suitable fire frequency protocol which will facilitate natural reproduction should be further studied. The post-burn fuel loads one year after the fire in the degraded pine forests were still lower than the pre-burn level indicating that a degraded pine forest at Nam Nao National Park requires more than one year of fire-free period to recover back to the pre-burn conditions (Wanthongchai et al. 2013).

\section{CONCLUSION}

Fire did affect the vegetation structure and composition of the degraded pine forest and the mixed oak-pine forest. Fire caused a significantly higher tree mortality in the degraded pine forest than in the mixed oak-pine forest of Phu Kum Khao, Nam Nao National Park, Thailand. The fire effects on the natural regeneration density, diameter and height was, however, not significant. This could be due to the highly varied fire behaviour in each experimental plot. However, the number of seedlings increased after the burning experiment probably due to more open spaces for the seeds to germinate and grow. Diameter of seedlings and saplings were only slightly different while the seedling ratio (sprout: seedling ratio) in the mixed oakpine forest was higher than in the degraded pine forest.

\section{ACKNOWLEDGEMENTS}

This study was supported by the Thailand Research Fund (TRF) and the Office of the Higher Education Commission, Thailand. The authors would like to thank the National Park, Wildlife and Plant Conservation Department for granting the permission to conduct this study in the Nam Nao National Park, Petchabun, Thailand. The authors are also grateful to all the staff of the Nam Nao National Park, and staff of the Petchabun forest fire control station for their valuable assistance throughout the fieldwork. Special thanks are also accorded to the Department of Silviculture, Faculty of
Forestry, Kasetsart University, Thailand, for providing a vehicle and equipment and to the students assisting in the fieldwork and to Miss Orathai Pongraktham for editing the English draft of this manuscript.

\section{REFERENCES}

Brown JK, Smith JK. 2000. Wildland fire in ecosystems: Effects of fire on flora. Gen Tech Rep RMRSGTR-42-vol.2. Ogden (US): USDA Forest Service.

Byram GM. 1959. Combustion of forest fuels. In: Davis KP, editor. Forest Fire: Control and Use. New York (US): McGraw-Hill. p. 61-89.

Chandler C, Cheney P, Thomas P, Trabaud L, Williams D. 1983. Fire in forestry, volume I. Forest fire behavior and effects. New York (US): John Willey \& Sons, Inc.

Cochrane MA. 2009. Tropical fire ecology: Climate change, land use, and ecosystem dynamics. Berlin (DE): Springer.

Goldammer JG, Penafiel RS. 1990. Fire in the pinegrassland biomes of tropical and subtropical Asia. In: Goldammer JG, editor. Fire in the Tropical Biota: Ecosystem Processes and Global Challenges Vol. 84. Berlin (DE): Springer-Verlag. p. 45-62.

Kimmins JP. 1997. Forest ecology: A foundation for sustainable management. New Jersey (US): Prentice Hall.

Kutintara U. 2008. Classification of vegetative cover in Thailand. J Trop Plants Res 1:1-21.

Pyne SJ. 2001. Fire: A brief history. Seattle (US): University of Washington Press.

Royal Forest Department. 2008. Pine Genetic improvement in Thailand. Bangkok (TH): Assembly Agricultural Cooperatives Thailand.

Tarusadamrongdet V. 2013. Fuel properties and fire behavior of degraded pine forest and pine - oak subcommunity at Nam Nao National Park, Phetchabun Province [Dissertation] Retrieved from Kasetsart University.

Wanthongchai K, Bauhus J, Goldammer JG. 2008. Nutrient losses through prescribed burning of aboveground litter and understorey in dry dipterocarp forest of different fire history. Catena 74:321-32.

Wanthongchai K, Goldammer JG. 2011. Fire management in South and Southeast Asia's seasonally dry forests: Colonial approaches, current problems, and perspectives. In: Mcshea WJ, Davies SJ, Bhumpakapun N, editors. The Ecology and Conservation of Seasonally Dry Forests in 
BIOTROPIA Vol. 27 No. 2, 2020

Asia. Washington DC (US): Smithsonian Wanthongchai K, Bauhus J, Goldammer JG. 2014. Institution Scholarly Press.

Wanthongchai K, Tarusadamrongdet V, Chinnawong K, Sooksawat K. 2013. Fuel properties and fire behaviour characteristics of prescribed fire in pinedominated forests at Nam Nao National Park, Thailand. Int J Wildland Fire 22:615-24.

Effects of past burning frequency on woody plant structure and composition in dry dipterocarp forest. Thai J For 33(3):109-30.

Whelan RJ. 1995. The ecology of fire. Melbourne (AU): Cambridge University Press Australia. 